\title{
Two rare anglesey discoid markers
}

\begin{abstract}
Small, round head-and-shaft funerary memorials have been referred to variously as discoid grave markers, ringed crosses or wheel cross. Their form and purpose differs from Cornish wayside crosses, German Scheibenkreuz and what are usually referred to as high crosses and are found, in various morphologies, throughout Europe and North America. These distinctive memorials are rare in Britain and previously unknown in Wales. Two undescribed discoid grave markers, recently found in Anglesey, are detailed and tentatively dated to the late eighteenth and early nineteenth centuries. Their typological and cultural context is discussed and their morphology compared with similar European and North American examples. Typological difficulties are explained and a complex origin of the disc-headed grave marker is suggested.
\end{abstract}

Keywords: discoid markers, funerary, Scheibenkreuz, ringed or wheel crosses, archaeology
Volume 5 Issue 4 - 2020

\author{
George Thomson \\ Craignish, The Loaning, Waterbeck, UK
}

Correspondence: George Thomson, Craignish, The Loaning, Waterbeck, Lockerbie, DGI I 3EY,Tel 0I46I600209,

Email georgel@georgethomsonlettering.com, georgethomsonbooks@gmail.com

Received: June 04, 2020 | Published: July 29, 2020

\section{Introduction}

Discoid grave markers are amongst the rarest forms of funerary memorial in Britain, although they have been recorded from many English counties. However, throughout mainland Britain it is likely that fewer than one hundred survive. Only thirty-two have been recorded from Scotland. ${ }^{1}$ As such they have an important place in the history of British material culture. In Ireland they are common throughout Ulster but few are found elsewhere on the island. ${ }^{2}$ Until now, none have been recorded from Wales. This paper describes two of these unrecorded gravestones from Anglesey and discusses their typological and cultural context. Round head-and-shaft gravestones have been referred to variously as discoids (more so in continental Europe and the USA) and ringed or wheel crosses, especially in Britain and Ireland. ${ }^{3}$ Problems of terminology are exacerbated by the occurrence of intermediate and transitional forms that do not fit neatly into any taxonomy. Because of this range of forms, from the discoid shape through to ringed or wheel crosses, the author proposed a typology for these grave markers and related forms in Scotland which is applicable to them elsewhere. ${ }^{4}$ The artefacts also raise the question of whether or not they were originally carved and erected as funerary memorials or, in some cases, if they were some other sort of marker and later utilised for that purpose.

It is important to note that in this context we are including only small, short-shafted markers and not what are usually referred to in archaeology as free-standing 'high' crosses or cross slabs, to which they are not typologically and only loosely related in their function. However, it is recognised that sometimes there may have been a reciprocal influences on their design. It is not always possible to determine when a cross is 'short-shafted' or 'long-shafted' although, in practice, the distinction is usually fairly clear cut. Broken heads from lost shafts, or those that have been deliberated shortened and reused, create obvious difficulties. Discoid grave markers are not functionally nor typologically related to Cornish wayside crosses, although their reuse, and the adaptation similar Scheibenkreuz in Germany for funerary purposes, confuses matters somewhat. ${ }^{5}$ In most of Britain, the re-employment of non-funerary markers as later gravestones, and the carving of later inscriptions on early stones, are not as prevalent as in Cornwall and Germany. With a few notable exceptions, we can be fairly confident that those still located in graveyards mark the site of a burial.

The discoid grave marker is just one specific type of head-andshaft memorial in which the circular element is dominant. This is important when we consider the cultural evolution of the artefact. The variety of forms exemplifies the difficulty of trying to pigeonhole the discoid type of grave marker. The term 'discoid' refers to the artefact's morphology and has nothing whatever to do with its function. In simple terms, a discoid grave marker is a funerary artefact formed of a distinct round head surmounted on a shaft, although we can encounter problems when the discal part of the marker is ovoid or otherwise not exactly round, or when the top of the memorial is partially discoid or 'necked'. ${ }^{6}$ The shape (but not the relative width) of the shaft is, to a great extent, irrelevant as a primary diagnostic element. Most shafts are rectangular or trapezoidal. A portion of the shaft of discoid and discoid cross markers in Britain and continental Europe was intended to be a supporting part of the memorial buried in the ground. In Britain and Ireland small discoid grave markers almost invariably have a very short, partly buried shaft, while the shaft of non-funerary marker 'crosses' are usually considerably longer, often mounted on a socket base. The most important characteristic of a discoid marker is the predominance of a circular or nearly circular apex. Vertical slab headstones, on which a surface circular design is cut, such as some of the Scottish early Christian cross slabs and some early eighteenthcentury headstones in Co. Fermanagh, are not discoid but may have a cultural affinity with discoid grave markers.

\section{Distribution}

Circular or oval-shaped sculptural artefacts have been utilised as grave markers by various European and North American cultures from the Villanovan and Orientalizing Periods in Bologna (Italy), between the end of the ninth to the end of the sixth centuries BC (Figure 1), and the classical Roman period to the present day. ${ }^{7}$ These distinctive artefacts are particularly common in some parts of Europe, including the Languedoc district of southern France, especially the Hérault and the department of Aude, the Basque region of northern Spain, some of which are very large reaching nearly two metres in diameter, the 
Basque region of south-western France, Portugal, northern Germany and north-western Ireland (Figures 2-4). In recent years more are being found and reported. The occurrence of pre-1800 discoid grave markers is much more extensive than previously thought, although problems of definition impinge on the accuracy of any estimate of their distribution. Ucla records discoid grave markers from twenty-one countries in Europe, Asia, Africa and North America but his criteria for inclusion are rather liberal and erroneously maps many that are not funerary including the Cornish wayside crosses. ${ }^{8}$ Conversely, he suggests that there are few in Bulgaria but many important discoid grave markers are found there (Figure 5). Not only do discoid grave markers span more than two millennia, they have been used by both Christian and Muslim cultures.

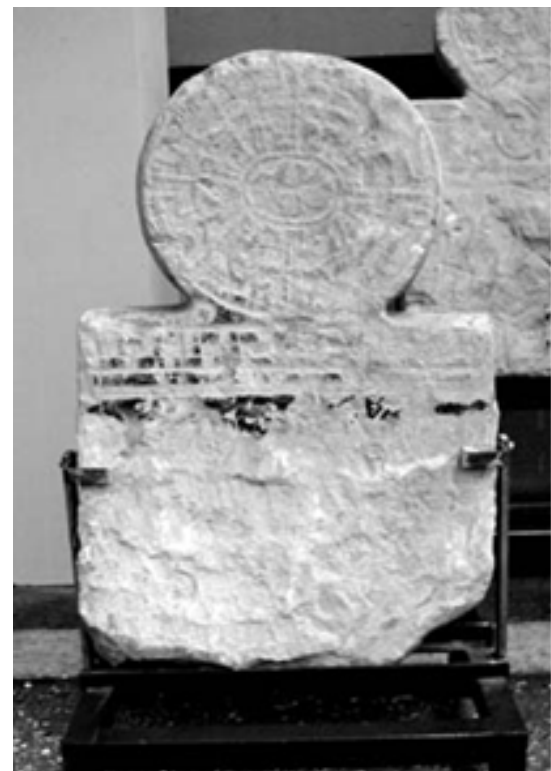

Figure I Discoid grave marker found at San Giovani in Persiceto, Orientalizing period 7th century BC, Bologna, Museo Civico Archeologico, Bologna. (photo George Thomson).

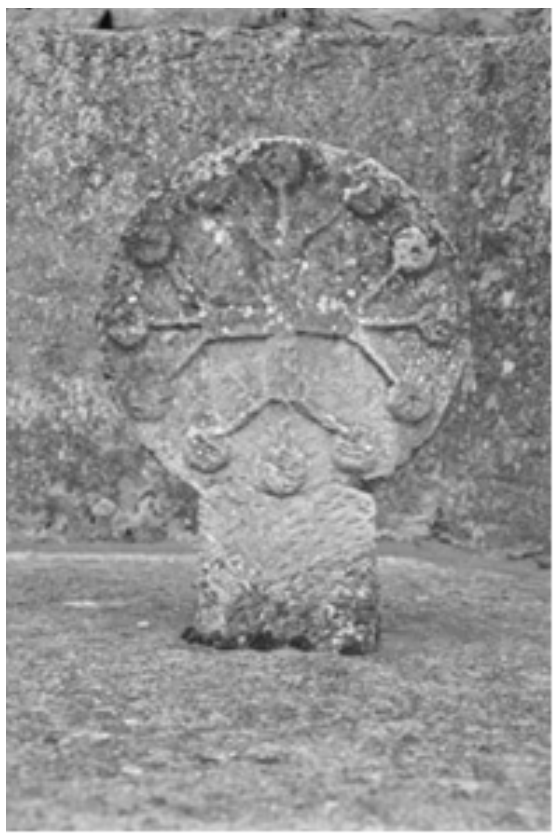

Figure 2 Medieval discoid grave marker, Airoux, Aude France, Languedoc region, France. (photo George Thomson).

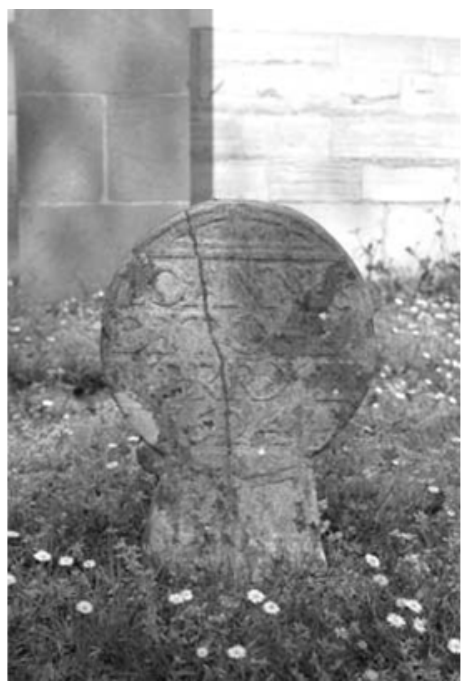

Figure 3 Discoid grave marker dated 1624, Larressore, Labourd, Basque region, France. (photo George Thomson).

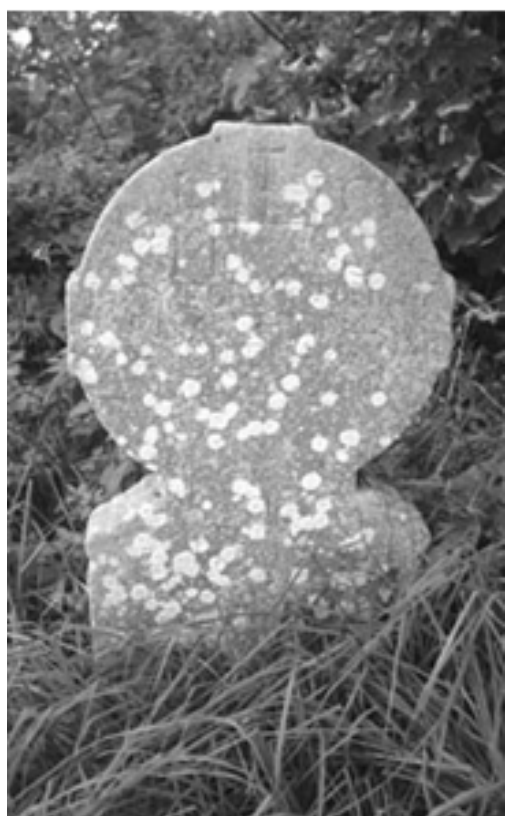

Figure 4 Discoid cross grave marker dated 1723, Donagh, Co. Fermanagh, Ireland. (photo George Thomson).

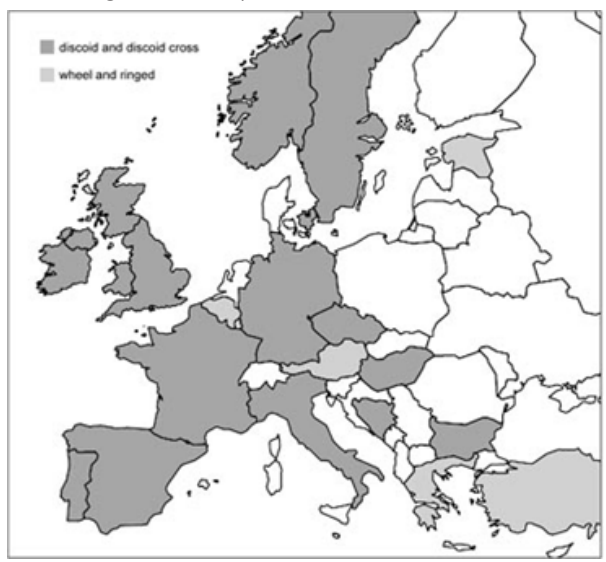

Figure 5 Map showing countries from which pre- 1800 discoid and discoid cross markers have been found. 


\section{Dating}

Dating uninscribed markers of this type is often difficult without contextual information. This is especially so with the small, simple types which date from the early medieval period up to the early eighteenth century. It is believed that the Languedoc memorials and many of the Spanish stones are from the early Middle Ages, probably ninth to twelfth centuries, with some of a later date. ${ }^{9}$ The majority of German discoid grave markers are in Hessen and are mostly from the late fifteenth to the early sixteenth century, though some are much later. ${ }^{10}$ In Navarra, the Pyrénées Atlantique, and less commonly in other parts of northern Spain, there are similar gravestones of the sixteenth to the nineteenth century, with modern 'revivals' made since the 1970s. Several English discoid grave markers are thought to be Anglo-Norman or Anglo-Saxon, while others are likely to be medieval. Only one medieval artefact which is certainly a discoid grave marker has been recorded from Ireland, on Devenish Island, Co. Fermanagh. ${ }^{11}$ British medieval forms tend to be simple, usually with no markings other than, rarely, an incised or relief cross. Postmedieval forms sometimes include initials, a short inscription or symbols of mortality. The later discoid markers are usually easy to date from inscriptions or, when the date is missing or obscure, from the lettering style and iconography.

\section{The anglesey markers}

Two discoid grave markers were found in Anglesey by the author in October 2016. The first was discovered at St Cyngar's Church, Llangadwaladr in the south-west of the island. This church is best known for the Cadfan Stone, a seventh-century memorial slab built into the interior north wall with an inscription commemorating King Cadfan of Gwynedd. The discoid marker lies against the exterior west wall of the south transept beside a gravestone dated 1799. The second discoid marker was found in the burial ground of Llaneilian Church in the north of Anglesey.

The St Cyngar's discoid marker (Figures 6\&7). St Cyngar's Church, Llangadwaladr, Anglesey, NGR SH383692. The dimensions of the St Cyngar's marker are:

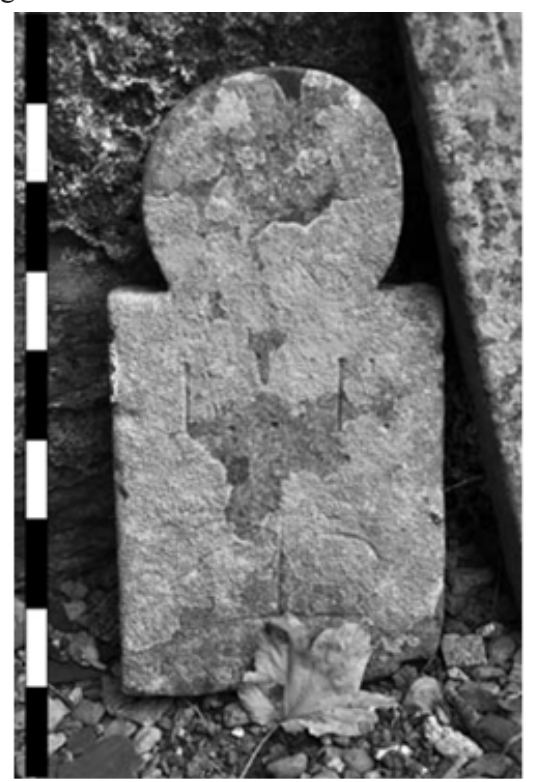

Figure 6 Discoid grave marker recto, St Cyngar's Church, Llangadwaladr, Anglesey. Scale divisions are $10 \mathrm{cms}$. (photo George Thomson).

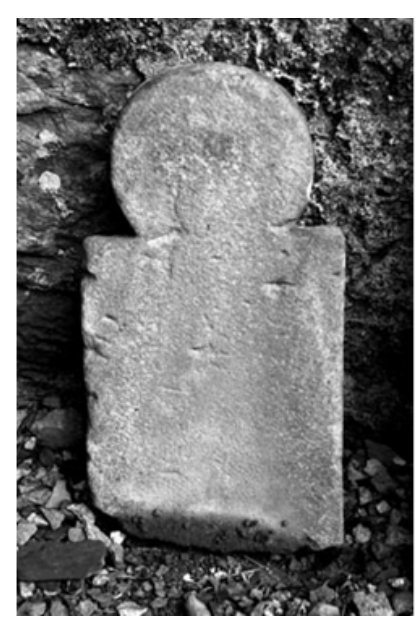

Figure 7 Discoid grave marker verso, St Cyngar's Church, Llangadwaladr, Anglesey. Scale divisions are $10 \mathrm{cms}$. (photo George Thomson).

\section{Total height $60 \mathrm{cms}$}

\section{Thickness $7.5 \mathrm{cms}$}

Shaft height $39 \mathrm{cms}$

\section{Shaft width $23.5 \mathrm{cms}$}

Diameter of disc head $21 \mathrm{cms}$

The disc head is perfectly circular and the shoulders of the shaft taper slightly downwards (towards the stone centre). The marker is carved from light coloured sandstone and is in relatively good condition. Figure 8 shows incised parts of the design on the obverse which are still identifiable and which are not simply artefacts in the stone. However, it is not possible to decipher what clearly are initials, nor the design below the initials. The lettering has been in light weight roman capitals as evidenced by the serifs which are still clearly visible but the three dots are anomalous. The reverse is blank. From the style of the marker, the material from which it is carved and the style of the lettering the St Cyngar's discoid grave marker is tentatively dated to the early eighteenth century.

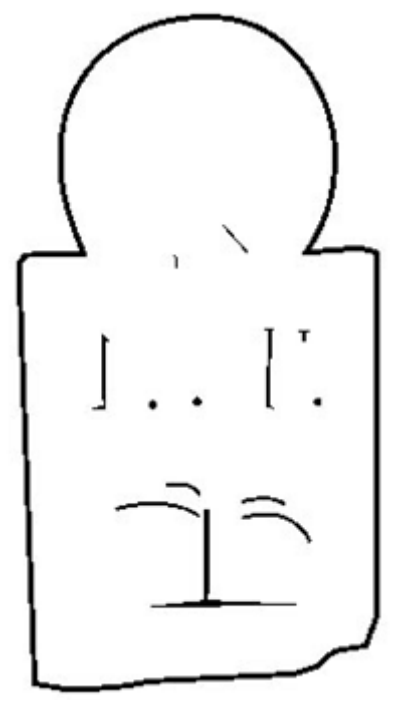

Figure 8 Identifiable carved elements on the discoid gravemarker from St Cyngar's Church, Llangadwaladr, Anglesey. 
The Llaneilian discoid marker (Figures 9\&10), Llaneilian Church, Llaneilian, Anglesey, NGR SH469929

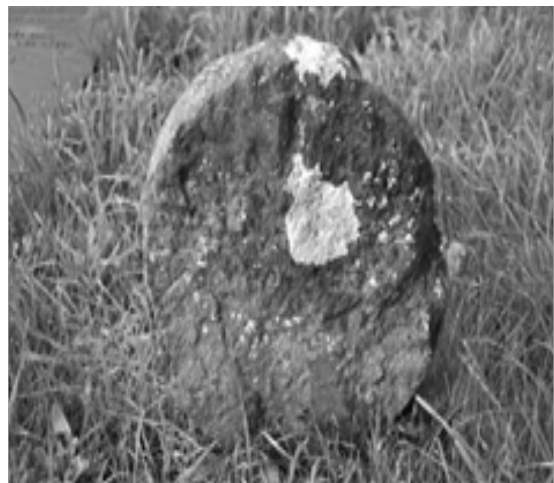

Figure 9 Discoid grave marker recto, Llaneilian Church, Anglesey. (photo George Thomson).

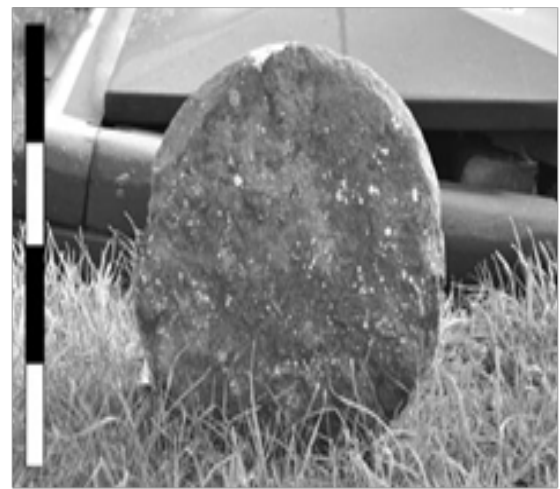

Figure 10 Discoid grave marker verso, Llaneilian Church, Anglesey. (photo George Thomson).

The dimensions of the Llaneilian marker are:

Diameter of disc head $37.5 \mathrm{cms}$

Thickness $9.5 \mathrm{cms}$ (maximum)

The discoid marker is perfectly circular and made from light brown sandstone which is in very poor condition. The disc head is set directly into the ground. The ground around the headstone was not excavated but it is likely that it has a short buried shaft. The obverse shows possible remains of an inscription but very little of this remains. The reverse is plain. The presence of a rudimentary inscription dates the stone to the post-medieval period, possibly late sixteenth or early seventeenth century. If there had been no inscription it would have been virtually impossible to determine if the marker was pre- or postmedieval.

\section{Context and discussion}

The simple, often plain discoid grave markers of the late AngloSaxon and early medieval periods in Britain vary in form surprisingly little throughout the period. Most have a very short shaft, usually trapezoidal in shape, which is often almost or completely buried. The disc head is rarely larger than $40 \mathrm{cms}$ in diameter. Southern European examples tend to be larger, some reaching massive proportions. The estelas gigantes at Barros in Cantabria, Spain are $1.75 \mathrm{~m}$ in diameter. Also, these early discoid markers from Spain, Portugal, and southern France usually have symbolic carving, much of which has yet to be deciphered, or a Christian cross. Post-medieval discoid markers from Britain, Ireland, the Basque region of Spain and the Basque and Languedoc regions of France are similarly carved with what is almost always Christian imagery or inscriptions. Mortality iconography is more common in Britain and Ireland than in Continental Europe. Although it is not possible to determine the nature of any carving which may have been on the Llaneilian discoid marker, it is clear that this artefact fits well with the British type. Although it cannot be ruled out, it is unlikely that the St Cyngar marker has been a footstone, as might be suggested by its size. In Britain it was common practise to carve initials on footstones, as in this marker, but symbolism or some other imagery on footstones is extremely rare. What appears to have been some sort of image on this artefact suggests it is almost certainly a headstone in spite of its small size. The small disc-head-and shaft St Cyngar discoid marker is the only funerary memorial of this specific form which dates from the early modern period reported from Britain, other than an undated eighteenth-century headstone from Mountfield in Sussex (Figure 11). However this has a proportionally larger disc head. A few other examples are found in continental Europe at Bosjökloster in Sweden and Tok in Hungary but they also have a proportionally larger diameter disc head. Some discoid headstones from Ulster approach this form but these are significantly larger, the disc head is at least as wide as the shaft and they are of a discoid cross or wheel cross form. Also, the shoulders of the shafts are usually shaped rather than square. An early eighteenth-century grave marker from Callowhill, Co. Fermanagh is also similar with a smaller diameter disc head (Figure 12). The date is partly eroded but it is probably late eighteenth or early nineteen century. The stone is much larger than the Anglesey example and the shoulders are stepped.

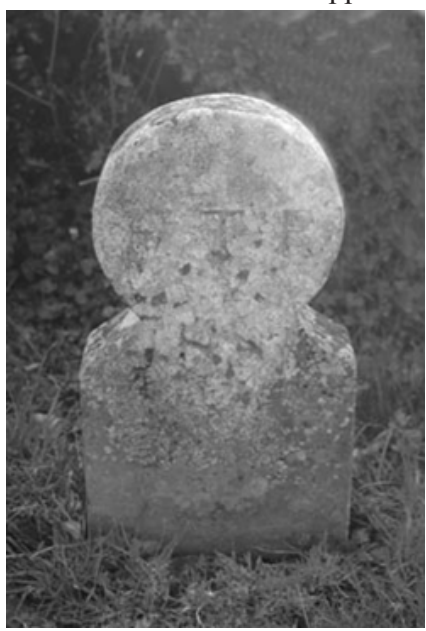

Figure I I Eighteenth century discoid gravemarker, Montfield, Sussex. (photo George Thomson).

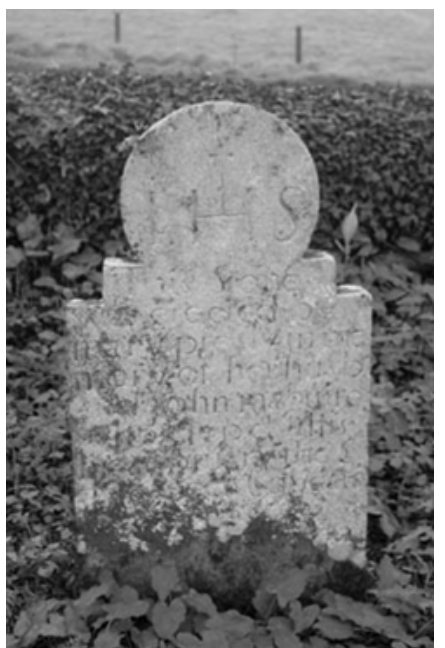

Figure 12 Discoid gravemarker 1729, Callowhill, Co. Fermanagh, Ireland. (photo George Thomson). 
Headstones of a similar head-and-shaft morphology are found in the USA, distributed throughout Arkansas, Illinois, Indiana, Kentucky, Missouri, North Carolina and Tennessee, although most are from the first half of the nineteenth century. Almost all stand well over a metre high. A characteristic of many of these headstones is a short 'neck' between the shaft and disc head (Figure 13). An interesting crude example from Indiana is reminiscent of the Llangadwaladr marker (Figure 14). Some wooden examples survive in the eastern states. An interesting small wooden marker of similar size to the Llangadwaladr stone was found nailed to a tree at Chattanooga, Tennessee. ${ }^{12}$ Several researchers have proposed that the discoid grave marker form is anthropomorphic and it is certainly the case that some similar artefacts have human faces carved on the disc head. ${ }^{13}$ Many of the sixteenthto eighteenth-century wooden krikštai grave markers from Lithuania are discoid in form and are certainly anthropomorphic. Some discoid grave markers from Halatte, Oise (France) are incised with the human figure, with the head on the discal part of the marker. A Bulgarian commemorative practice was to use a trapezoidal gravestone to mark the burial of the male deceased and a discoid gravestone for the female. Couples were often marked with the two forms joined as single memorial. ${ }^{14}$ Classical discoid markers and many of those in the Basque region are decorated with abstract representations of the sun or stars reflecting the importance of these astral bodies to those by or to whom they were erected. While this may have influenced the shape of the stones, it is doubtful if it was the primary reason for their morphology.

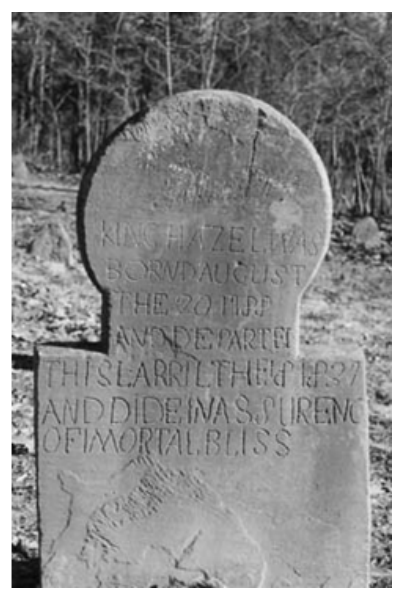

Figure 13 Necked discoid headstone 1837, Hazel Cemetery, Illinois, USA. Note the 'neck' between the shaft and the disc head. (photo Mike McNerney).

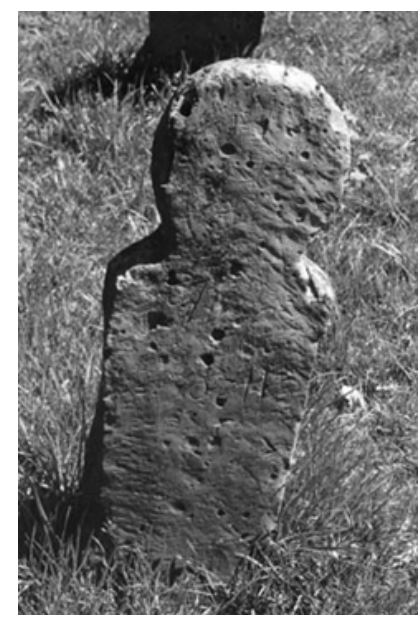

Figure 14 Crudely inscribed discoid grave marker probably late I8th century, Evans Family Cemetery, New Pekin, Indiana, USA. Note the damaged discoid marker in the background. (photo Mike McNerney).
The ringed cross has a quite different origin. Redknap and Lewis suggest it may have evolved from the laurel crown that often surrounds the cross on early Continental sarcophagi but it is generally accepted that this has pre-Christian origins being similar to the so-called 'sun cross' of Bronze Age Europe. ${ }^{15}$ Another theory for the origin and eventual choice of the discoid form for grave markers is a cultural empathy with geometry, especially the circle. ${ }^{16}$ Geometry brings order to visual complexity. It helps to organise visual thought and describe much of what we see around us. In terms of design, basic geometric shapes such as the rectangle and circle provide the functional basis of many of the things we utilise today. Many artefacts have a basic circular form. The practicality of the shape led to the wheel and determines the form of most coins and ceramics, for example. The human aspiration for order and the simplicity of the circular form was, perhaps, one of the determining factors, possibly the most important, in the origin of the discoid marker. It is probable, however, that each of the theories of their origin has some validity and all may have been instrumental, with different emphasis at different times in different cultures. ${ }^{17-23}$

\section{Acknowledgments}

I thank Mike McNerney of Carbondale, Illinois for permission to use his images of necked discoid gravestones.

\section{Funding}

None.

\section{Conflicts of interest}

Author declares that there is no conflict of interest.

\section{References}

1. G Thomson. A discoid marker from Collace, Perthshire. Scot Arch J. 2009;31(1-2):107-114.

2. G Thomson. Irish discoid gravemarkers and inscriptional lettering. Breifne. 2006;11:247-273.

3. G Thomson. Irish discoid gravemarkers. Archaeology Ireland. 2006;20(3):10-14;

4. H Mytum, R Evans. The 18th and 19th century graveyard monuments of Killeevan, Co. Monaghan and Galloon, Co. Fermanagh. Clogher Record. 2003;18(1):1-31.

5. J Nijssen. Les discoïdales et leurs alternatives dans le nord-ouest du continent. Hil Harriak, Actes du Colloque International sur la Stèle Discoidales. 1984;347-360.

6. G Thomson. Contextualisation and typology of disc-headed and trapezoidal gravemarker forms in Scotland. Scot Arch J. 2012;34(5):1-24.

7. J Azzola, FK Azzola. Medieval Scheibenkreuz-Grabsteine in Hessen. ZHG. 1971;82:9-61.

8. MJ McNerney, H Meyer. Early pioneer gravestones of Pope County, Illinoi.s Carbondale; 1994.

9. H Prades.

10. The Gallo-Roman discoidal stele of Lattes. In: J Bousquet, editors. Archaeology en Languedoc special number. 1980;11-12.

11. E Frankowski. Discoid stelae of the Iberian Peninsula. Madrid: 1920.

12. PM Padovani. The Villanovan stele of Bologna. 1977;7.

13. P Ucla. The funeral steles evaluation test of our knowledge about funeral steles. In: C de la Casa, editors. V Congreso International de Estelas Funerarias: Actas, 1993. p. 725-731. 
14. J Bousquet. Discoidal steles. Archaeology en Languedoc special number $1980 ; 1-18$

15. Azzola, Azzola. Medieval disc cross tombstones in Hessen. Old Thuringia. $1977 ; 14$.

16. H. Hickey. Images of stone. Figure sculpture in the Lough Erne Basin Antiquity. 1978.

17. G Thomson. Vernacular memorials. Creativity in the graveyard Waterbeck. 2011.

18. J Etcheverry, M Duvert, M Etchehandy, et al. Discoid stelae and Basque funerary art. Hil harriak. Bayonne. 2004.
19. M. Marchesi. The sculptures of the Orientalizing age in Etruria Padana. Bologna. 2011.

20. JM Redknap, JM Lewis. A corpus of early medieval inscribed stones and stone sculpture in Wales, 1 South-east Wales and the English border. Cardiff. 2007.

21. M Eliade. Images and symbolism: Studies in religious symbolism. Princeton. 1961.

22. FM Etchehandy. Basque discoidal stelae 2. Zodiaque. 1989;161:22-33.

23. R Aussibal. From the Roman discoidal stele to modern and current forms. In: C del la Casa, editor. V International Congress of Funeral Steles: Minutes. 1993;631-637. 